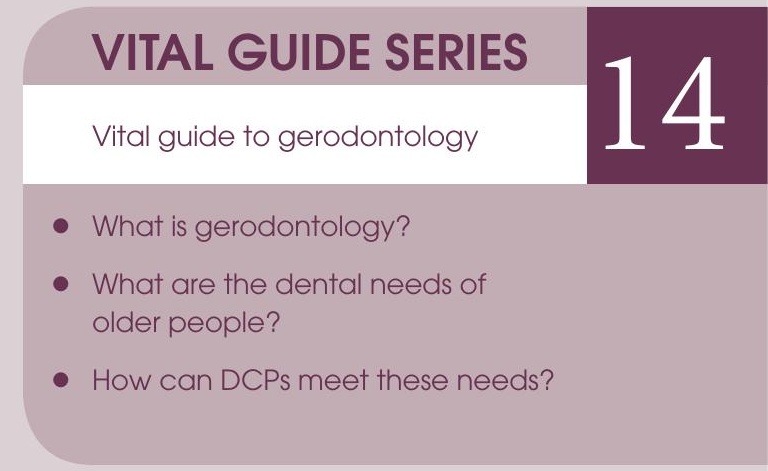

\title{
VITAL GUIDE TO
}

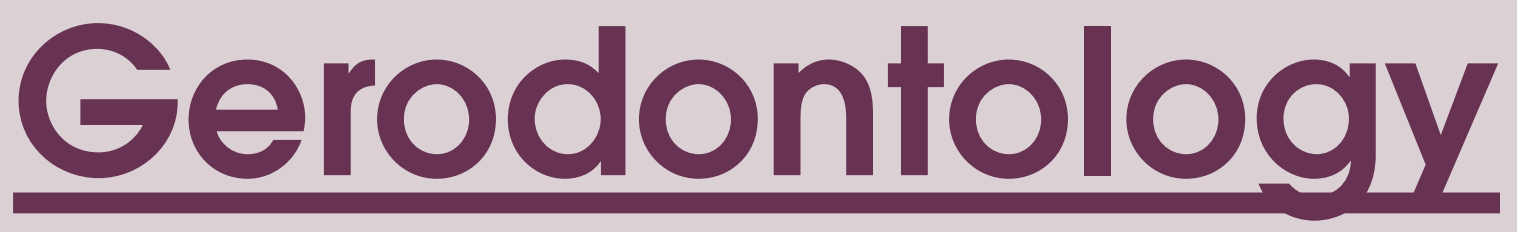

\section{Michael Watson introduces Vital to the dental specialty concerning the oral health issues specific to the older members of the population.}

I first set up a practice in a small North Essex town just over 30 years ago. There was no dentist within ten miles in any direction so there was a great deal of unmet demand. The year I set it up was 1978, the same year as the second Adult Dental Health Survey, ${ }^{1}$ which found that $30 \%$ of the adult population had no teeth. It seemed at times as if they were all beating a path to our door, but I used a very experienced technician and the patients seemed to go away happy with their new dentures.

That was as far as gerodontology went for us in those days. Fast forward 30 years and

\section{'The last}

\section{Adult Dental}

Health Survey predicted that

\section{in 2028 tooth}

\section{loss would}

be almost

eliminated in

those under 75.'

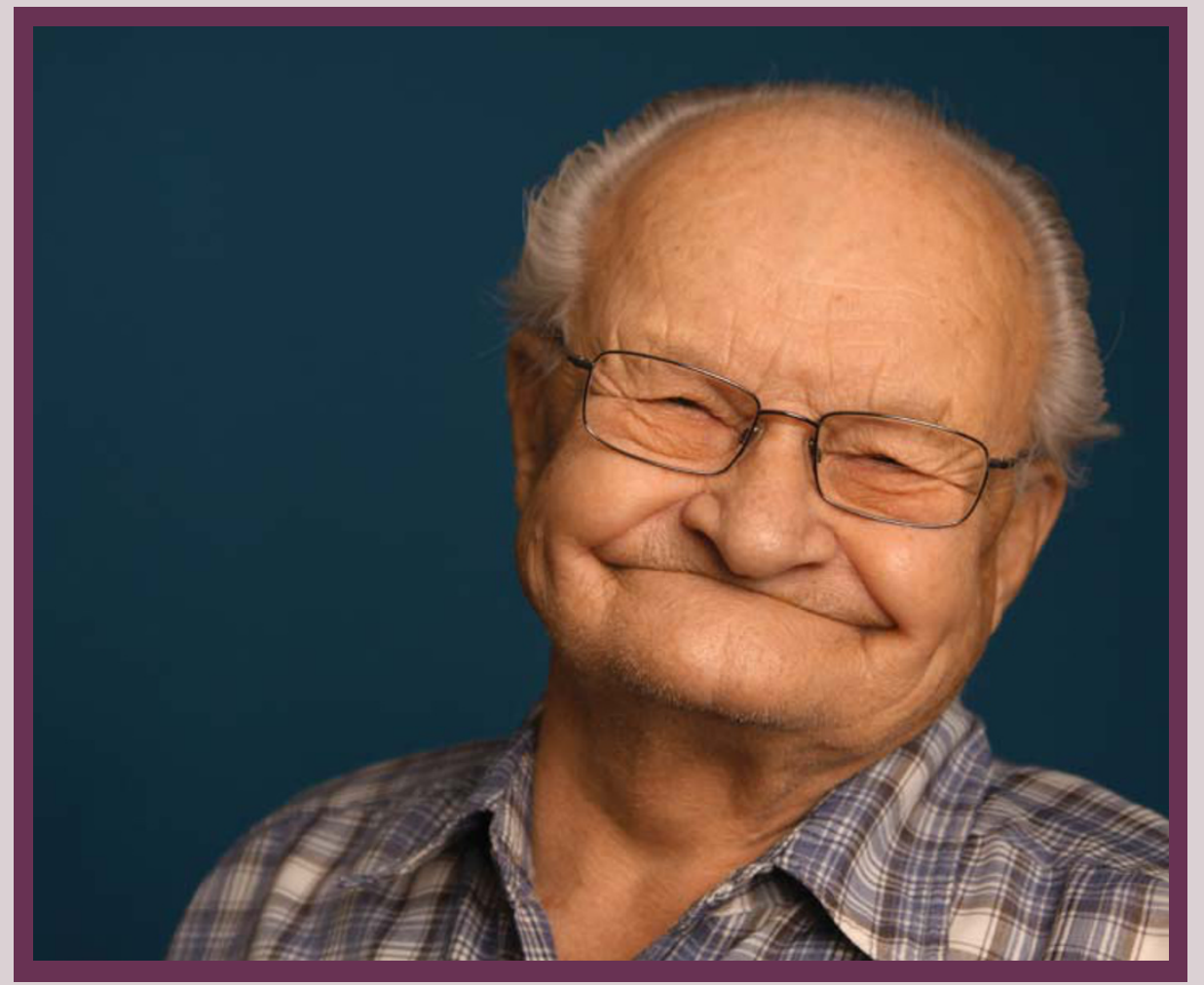

I have now retired. Far from being edentulous, people of my age have most if not all of our own teeth and aim to keep it that way. This contrasts with 1978 when $80 \%$ of over 65 -year-olds had lost all their teeth. The next Adult Dental Health Survey will be carried out this year, but the last one predicted that in 20 years time (2028) total tooth loss would be almost eliminated in those under 75 . Only the over 85 -year-olds would have appreciable numbers without teeth.
The lessons to be learned from these figures are that the typical older person of the future will have most of their own teeth. Those who need full dentures, however, will be older, less mobile, less able to look after their oral health and more likely to be in residential care. Add to this the fact that the 'Baby Boomer' generation is now approaching pension age with teeth that were heavily restored in their adult years. A recent BDA publication ${ }^{2}$ described the problems of this age group: 


\section{VITAL GUIDE}




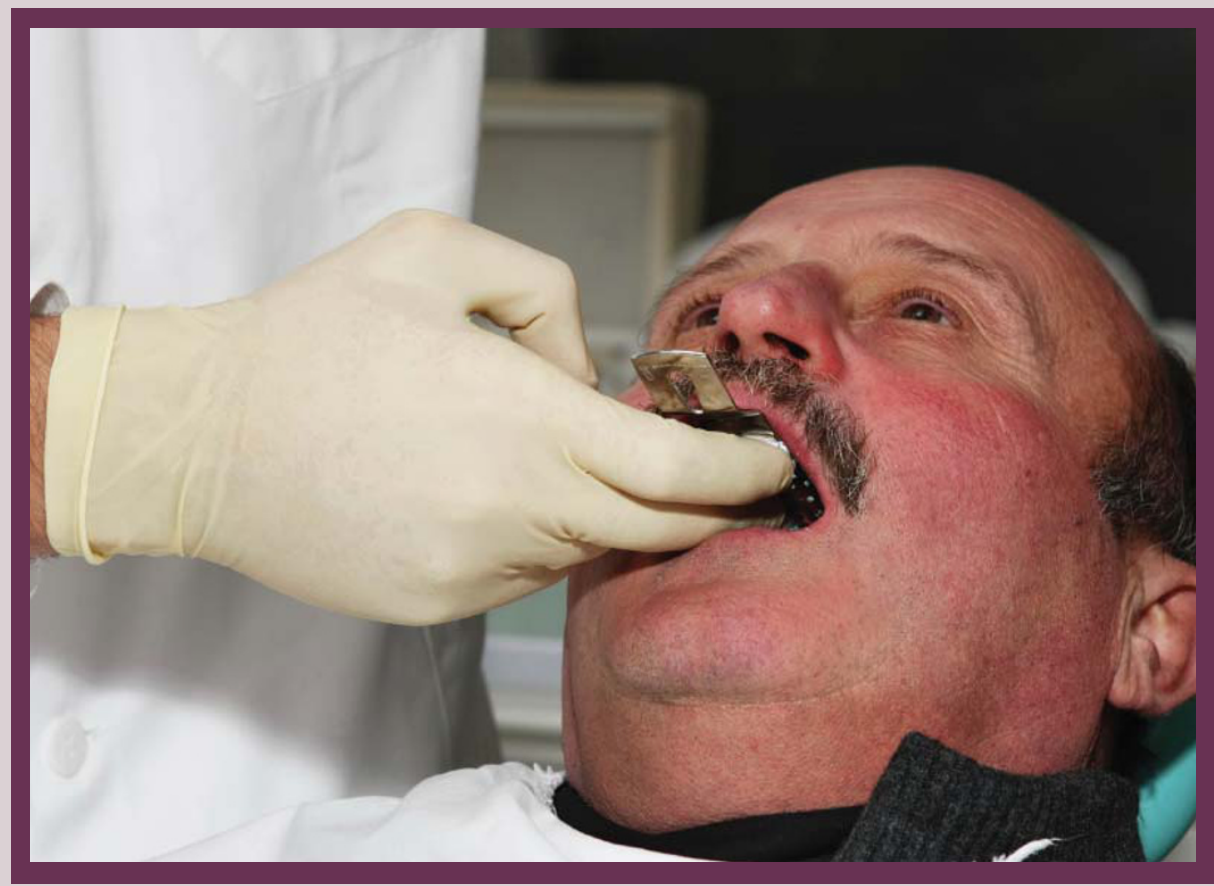

We should also not forget those who wear dentures whether complete or partial. They may have worn them for years, but find them more difficult to cope with in old age. They may have worked hard to keep their teeth but when the time comes that they must have some or all extracted, they may well resent this and find it hard to adapt to wearing them. They may also have problems going to a practice and need domiciliary care.

So how can dental care professionals (DCPs) help this ever-increasing sector or our society? The General Dental Council has recently outlined the scope of practice that DCPs can undertake. ${ }^{3}$ These include for the first time clinical dental technicians (CDTs) who could play an increasing role in the dental care of the older person. Overall there are increased roles for all DCPs; for instance dental nurses now should 'monitor, support and reassure patients' as well as giving 'appropriate advice to patients.'

The care of the elderly whether it is their physical or mental needs or the care of their mouth and dentition depends on how well the carer or health professional gets on with this age group. Going back to my early days of providing dentures to one and all, one of my team was a nurse, who spent much more of her time talking to the older patients and listening to their problems than mixing alginate. Some people get on with that age group better than others, just the same as some work well with children. Increasingly those who can look after the older patients will be valuable members of the dental team.

Three years ago the British Society of Gerodontology ${ }^{\star}$ published a review ${ }^{4}$ which suggested ways of meeting an unprecedented demand from older people for dentistry. Commenting on this review in the British Dental Journal, Editor-in-Chief Stephen Hancocks wrote: 'there will also be a need for prevention since, just as with oral diseases in all ages of people they are preventable.'

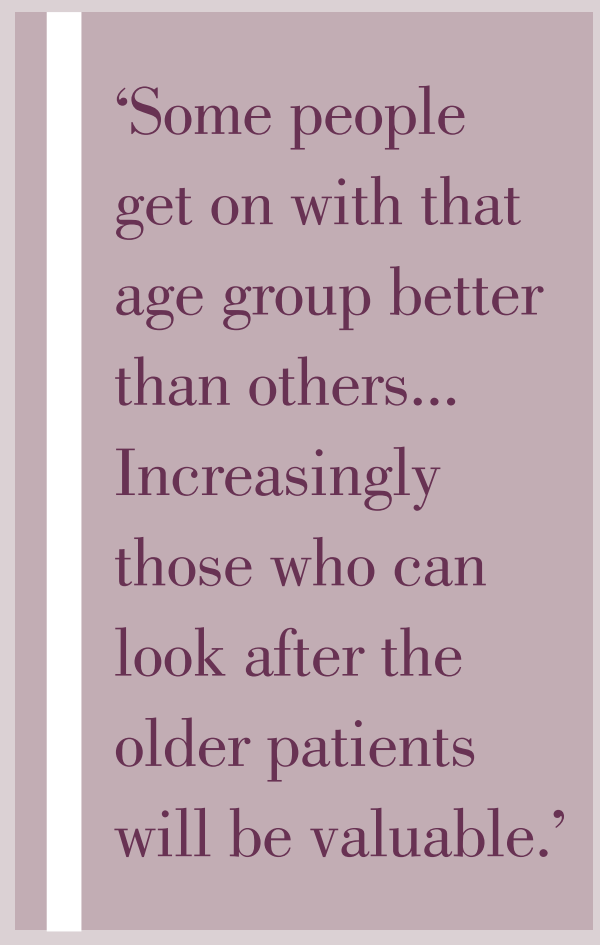

It is here that the role of dental hygienists and dental therapists will come into its own, not just for the older patients themselves. oral hygiene measures, diet control and fluorides is just as important for this group as for all others and will also need to be incorporated more comprehensively into their future care.' It will also be important to work with their Stephen Hancocks again: 'The application of carers to help this age group help themselves. Talking to carers about the oral health needs of the elderly will be needed more in the future.

1. Adult Dental Health Survey, 1998. Office of National Statistics, The Stationery Office.

2. Oral Healthcare for Older People: 2020 Vision, a BDA Key Issue Policy Paper: May 2003.

3. Scope of practice - who can do what in the dental team. General Dental Council, 2008.

4. Department of Health. Meeting the challenges of oral health for older people: a strategic review. Gerodontology 2005; 22 Suppl 1: 3-48.

5. Hancocks S. Older oral health. Br Dent J 2006; 200: 1 .

${ }^{\star}$ British Society of Gerodontology: www.gerodontology.com

\section{Test yourself}

1. In 1978, what proportion of people over age 65 had lost all their teeth? A. $80 \%$

B. $20 \%$

\section{Thirty percent of the adult population in 1978: \\ A. had no teeth \\ B. wore dentures}

\section{In 2028 the predictions are that:}

A. tooth loss will be almost eliminated in everyone

B. tooth loss will be almost eliminated in under $75 \mathrm{~s}$

\section{DCPs can:}

A. play an important role in preventive care for older patients

B. help older patients to help themselves

'g puo $\forall \nabla^{\prime}$ ' $\varepsilon^{\prime} \forall 乙^{\prime} \forall L$ :sıөмsu

Correction notice: In the last issue, the Vital guide to paediatric dentistry (spring 2009 pages 17-19) stated that the author, Laura Gartshore, is at Leeds Dental Institute. She is actually at the University of Liverpool School of Dental Sciences. Apologies to Laura! 